\title{
Device Available for Evaluation
}

National Cancer Institute

\section{Source}

National Cancer Institute. Device Available for Evaluation. NCI Thesaurus. Code C53449.

Indicates whether the device is available for evaluation by the manufacturer. 